\title{
Cytogenetic study on antlions (Neuroptera, Myrmeleontidae): first data on telomere structure and rDNA location
}

\author{
Valentina G. Kuznetsova', Gadzhimurad N. Khabiev², Boris A. Anokhin' \\ I Zoological Institute, Russian Academy of Sciences, Universitetskaya nab. 1, 199034, St. Petersburg, Russia \\ 2 Prikaspiyskiy Institute of Biological Resources, Dagestan Scientific Centre, Russian Academy of Sciences, ul. \\ M. Gadzhieva 45, 367025 Makhachkala, Russia
}

Corresponding author: Valentina G. Kuznetsova (valentina_kuznetsova@yahoo.com)

Academiceditor:I. Gavrilov-Zimin|Received 10October 2016|Accepted8November2016|Published25November 2016

http://zoobank.org/727F8610-AFBB-4FA2-BC26-0D97A7A3135B

Citation: Kuznetsova VG, Khabiev GN, Anokhin BA (2016) Cytogenetic study on antlions (Neuroptera, Myrmeleontidae): first data on telomere structure and rDNA location. Comparative Cytogenetics 10(4): 647-656. doi: 10.3897/CompCytogen.v10i4.10775

\begin{abstract}
Myrmeleontidae, commonly known as "antlions", are the most diverse family of the insect order Neuroptera, with over 1700 described species (in 191 genera) of which 37 species (in 21 genera) have so far been studied in respect to standard karyotypes. In the present paper we provide first data on the occurrence of the "insect-type" telomeric repeat (TTAGG) ${ }_{n}$ and location of $18 \mathrm{~S}$ rDNA clusters in the antlion karyotypes studied using fluorescence in situ hybridization (FISH). We show that males of Palpares libelluloides (Linnaeus, 1764) (Palparinae), Acanthaclisis occitanica (Villers, 1789) (Acanthaclisinae) and Distoleon tetragrammicus (Fabricius, 1798) (Nemoleontinae) have rDNA clusters on a large bivalent, two last species having an additional rDNA cluster on one of the sex chromosomes, most probably the X. (TTAGG) ${ }_{n}$ - containing telomeres are clearly characteristic of $P$. libelluloides and A. occitanica; the presence of this telomeric motif in D. tetragrammicus is questionable. In addition, we detected the presence of the (TTAGG) ${ }_{n}$ telomeric repeat in Libelloides macaronius (Scopoli, 1763) from the family Ascalaphidae (owlflies), a sister group to the Myrmeleontidae. We presume that the "insect" motif (TTAGG) ${ }_{n}$ was present in a common ancestor of the families Ascalaphidae and Myrmeleontidae within the neuropteran suborder Myrmeleontiformia.
\end{abstract}

\section{Keywords}

TTAGG, rDNA, fluorescence in situ hybridization, Palpares libelluloides, Acanthaclisis occitanica, Distoleon tetragrammicus, Libelloides macaronius, Myrmeleontidae, Ascalaphidae, Neuroptera

Copyright Valentina G. Kuznetsova et al. This is an open access article distributed under the terms of the Creative Commons Attribution License (CC BY 4.0), which permits unrestricted use, distribution, and reproduction in any medium, provided the original author and source are credited. 


\section{Introduction}

The ends of eukaryotic chromosomes are capped with complex nucleoprotein structures, the telomeres, which preclude fusion, recombination and degradation of the chromosome ends and thus maintain the genome integrity. In a large number of organisms, telomeric DNA consists of highly repetitive short sequences. Although telomeres are diversified in their DNA sequence composition in different eukaryotic groups, several phylogenetic lineages demonstrate highly conserved motifs. In animals, three main types of telomeric repeats are known: TTAGGG, TTAGGC, and TTAGG. Motif (TTAGGG) prevails in the multicellular animals, except roundworms and arthropods, and is probably ancestral for all Metazoa; motif (TTAGGC) is characteristic of nematodes; motif (TTAGG), which is a derivative of (TTAGGG) ${ }_{n}$, occurs in all arthropod groups (sea spiders, chelicerates, myriapods, crustaceans, and hexapods), supporting their origin from a common ancestor (Traut et al. 2007, Gomes et al. 2010). The (TTAGG) ${ }_{n}$ telomeric motif is commonly found among different higher insect taxa, and this telomere structure is supposed to be phylogenetically ancestral in the class Insecta in general (Frydrychová et al. 2004). However, the insect-type consensus telomeric sequence is known to be lost independently during insect evolution (Frydrychová et al. 2004, Lukhtanov and Kuznetsova 2010, Gokhman et al. 2014). Further on, the loss and subsequent gain of typical telomeres may occur repeatedly as it has been indicated in Coleoptera (Frydrychová and Marec 2002) and recently in Heteroptera (Pita et al. 2016). However, it is worth noting that the number of species with known telomere structure is extremely low in each insect order, including Neuroptera (Frydrychová et al. 2004).

Neuroptera, also known as Planipennia, are a highly heterogeneous insect order, with 5803 species described in 16 families (Oswald 2016). In this group, telomere structure has so far been described in only two species, Protidricerus japonicus (McLachlan, 1891) from the family Ascalaphidae (Okazaki et al. 1993) and Chrysoperla carnea (Stephens, 1836) from the family Chrysopidae (Frydrychová et al. 2004). The former species was found to have the insect-type telomeric motif (TTAGG), whereas the latter species was reported to lack this motif. Considering the heterogeneity in the presence of the TTAGG telomeric repeats discovered in Neuroptera, it thus could be interesting to verify the presence of this motif in other members of the order.

Within Neuroptera, the family Myrmeleontidae, commonly known as "antlions", due to the fiercely predatory habits of their larvae, is the most diverse group having worldwide distribution. This family is considered monophyletic, with over 1700 extant species in 191 genera. In Myrmeleontidae, as many as 12 subfamilies, among them Palparinae, Pseudimarinae, Stilbopteryginae, Dimarinae, Echthromyrmicinae, Dendroleontinae, Nemoleontinae, Glenurinae, Myrmecaelurinae, Acanthaclisinae, Brachynemurinae, and Myrmeleontinae (Krivokhatsky 2011), but most commonly only three, Stilbopteryginae, Palparinae and Myrmeleontinae (Stange 2004, Badano et al. 2016), are recognized. Myrmeleontidae, together with the families Psychopsidae, Nemopteridae, Nymphidae and Ascalaphidae, form the monophyletic suborder Myr- 
meleontiformia (= the superfamily Myrmeleontoidea) that is a derived lineage of Neuroptera diversified in the Jurassic period (Badano et al. 2016). Different phylogenetic analyses based on morphological and genetic data established a sister-group relationship between Myrmeleontidae and Ascalaphidae (Badano et al. 2016). Ascalaphidae, or owlflies, are a smaller family, with about 430 described species in 100 genera distributed in all the biogeographic regions (Tjeder 1992). The family is subdivided into two main subfamilies, Haplogleniinae and Ascalaphinae (Henry 1978).

Until now, the cytogenetic studies in the Myrmeleontidae have been carried out on 37 species from 21 genera, and were focused exclusively on the basic features of the karyotypes such as chromosome numbers and sex determination systems (reviewed in Kuznetsova et al. 2015).

The aim of the present study is to further characterize chromosomes of antlions and to study their evolution by exploring the telomere structure and chromosomal location of the major ribosomal RNA (rRNA) genes using fluorescence in situ hybridization (FISH). The FISH technique was applied for the first time in the family Myrmeleontidae.

We examined the presence/absence of TTAGG telomeric repeats and location of the rDNA clusters in Palpares libelluloides (Linnaeus, 1764), Distoleon tetragrammicus (Fabricius, 1798) and Acanthaclisis occitanica (Villers, 1789) from the family Myrmeleontidae. In addition, we studied telomere structure in Libelloides macaronius (Scopoli, 1763) belonging to the sister family Ascalaphidae.

\section{Material and methods}

\section{Material}

Three antlion species, involving three different genera from three subfamilies (sensu Krivokhatsky 2011), i.e. Palparinae (P. libelluloides), Nemoleontinae (D. tetragrammicus) and Acanthaclisinae (A. occitanica), as well as the only owlfly species from the subfamily Ascalaphinae (L. macaronius) were studied. The specimens were collected by G. Khabiev from May to October 2015 in the Republic of Dagestan (North-East Caucasus, Russia). In the field, adult individuals were fixed in a solution of $96 \%$ alcohol and glacial acetic acid $(3: 1)$ and then stored at $4{ }^{\circ} \mathrm{C}$ until required. Collection localities and chromosomal traits of each species are given in Table 1.

\section{Telomere and rDNA detection by FISH}

Chromosome preparations were obtained from male gonads. Testes were dissected in a drop of $45 \%$ acetic acid and squashed. The coverslips were removed using dry ice. Prior to FISH treatment, the preparations were examined using phase contrast microscopy. 
Table I. Examined material and main karyotypic features obtained during the present study.

\begin{tabular}{|c|c|c|c|c|c|}
\hline Taxon & $\begin{array}{l}\text { Sampling locality and } \\
\text { month and year of } \\
\text { collection }\end{array}$ & $\begin{array}{c}\text { Number of } \\
\text { studied males }\end{array}$ & $\begin{array}{c}\text { Diploid } \\
\text { karyotype }\end{array}$ & $\begin{array}{l}\text { Telomeric } \\
\text { sequence }\end{array}$ & $\begin{array}{c}18 S \text { rDNA } \\
\text { clusters location }\end{array}$ \\
\hline \multicolumn{6}{|l|}{ MYRMELEONTIDAE } \\
\hline \multicolumn{6}{|l|}{ Palparinae } \\
\hline $\begin{array}{l}\text { Palpares libelluloides } \\
\text { (Linnaeus, 1764) }\end{array}$ & \begin{tabular}{|c|} 
Russia, Dagestan, \\
near Makhachkala \\
$42^{\circ} 59^{\prime} 59.6^{\prime \prime} \mathrm{N} 47^{\circ} 13^{\prime} 33.0^{\prime \prime} \mathrm{E}$, \\
VI.2015 \\
\end{tabular} & 2 & $24+X Y$ & $(\text { TTAGG })_{n}$ & $\mathrm{AA}^{*}$ \\
\hline \multicolumn{6}{|l|}{ Nemoleontinae } \\
\hline $\begin{array}{l}\text { Distoleon } \\
\text { tetragrammicus } \\
\text { (Fabricius, 1798) }\end{array}$ & \begin{tabular}{|c|} 
Russia, Dagestan, near \\
Makhachkala \\
$43^{\circ} 00^{\prime} 28.7^{\prime \prime N ~} 47^{\circ} 14^{\prime} 51.3^{\prime \prime} \mathrm{E}$ \\
VII. 2015
\end{tabular} & 2 & $14+X Y$ & ?** & $A A+X$ \\
\hline \multicolumn{6}{|l|}{ Acanthaclisinae } \\
\hline $\begin{array}{l}\text { Acanthaclisis } \\
\text { occitanica } \\
\text { (Villers, 1789) }\end{array}$ & \begin{tabular}{|c|} 
Russia, Dagestan, \\
near Makhachkala \\
$43^{\circ} 00^{\prime} 28.7^{\prime \prime N ~} 47^{\circ} 14^{\prime} 51.3^{\prime \prime} \mathrm{E}$ \\
VII. 2015 \\
\end{tabular} & 2 & $16+X Y$ & $(\text { TTAGG })_{n}$ & $A A+X$ \\
\hline \multicolumn{6}{|l|}{ ASCALAPHIDAE } \\
\hline \multicolumn{6}{|l|}{ Ascalaphinae } \\
\hline $\begin{array}{l}\text { Libelloides } \\
\text { macaronius } \\
\text { (Scopoli, 1763) }\end{array}$ & $\begin{array}{c}\text { Russia, Dagestan, } \\
\text { near Gelinbatan village } \\
41^{\circ} 56^{\prime \prime} 50^{\prime \prime} \mathrm{N}, 48^{\circ} 10^{\prime \prime} 2^{\prime E} \mathrm{E} \\
\text { VII. } 2015\end{array}$ & 1 & _*** & $\left(\right.$ TTAGG) ${ }_{n}$ & _*** \\
\hline
\end{tabular}

*A pair of autosomes; ${ }^{* *}$ Ambiguous data; ${ }^{* * *}$ Missing data

FISH with (TTAGG) ${ }_{n}$ and $18 \mathrm{~S}$ rDNA probes was applied as previously reported for some other insects (Kuznetsova et al. 2015, Maryańska-Nadachowska et al. 2016, Golub et al. 2016). In brief, chromosome preparations were treated with $100 \mu \mathrm{g} / \mathrm{ml}$ RNase A and $5 \mathrm{mg} / \mathrm{ml}$ Pepsin solution to remove excess RNA and proteins. Chromosomes were denatured on a slide in a hybridization mixture with biotinylated $18 \mathrm{~S}$ rDNA probe from the genomic DNA of Pyrrhocoris apterus (Linnaeus, 1758) and rhodaminated (TTAGG) ${ }_{n}$ probe with addition of salmon sperm DNA and then hybridized for 36 h. Hybridization signals were detected with NeutrAvidin-FITC.

Chromosomes were mounted in antifade medium (ProLong Gold antifade reagent with DAPI; Invitrogen) and covered with a glass coverslip. Chromosome slides were analyzed under a Leica DM 6000 B microscope. Images were taken with a Leica DFC 345 FX camera using Leica Application Suite 3.7 software with an Image Overlay module.

\section{Results}

In male P. libelluloides, we found 12 autosomal bivalents and $\mathrm{X}$ and $\mathrm{Y}$ univalent chromosomes (Fig. 1), confirming the chromosome number, $2 \mathrm{n}=26(24+\mathrm{XY})$, reported 


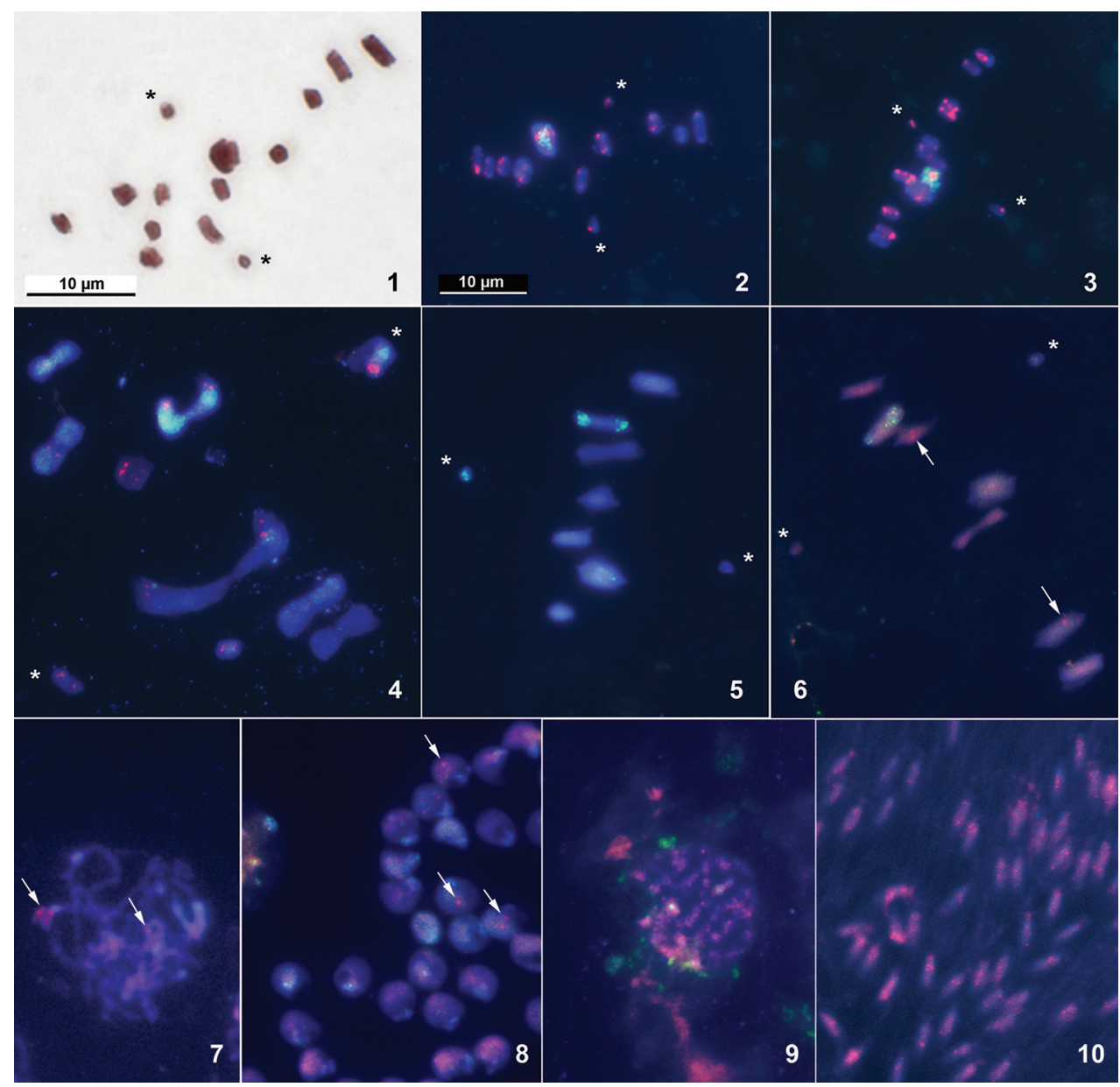

Figures I-I 0. Different stages of spermatogenesis in antlion species Palpares libelluloides (I-3), Acanthaclisis occitanica (4), Distoleon tetragrammicus (5-8) and owlfly species Libelloides macaronius (9-10) after standard staining (I) and FISH with the $18 \mathrm{~S}$ rDNA and telomeric (TTAGG) ${ }_{n}$ probes (2-I0). I-3 MI, $\mathrm{n}=12+\mathrm{X}+$ Y 4 diakinesis/MI transition, $\mathrm{n}=8+\mathrm{X}+\mathrm{Y} \mathbf{5}, \mathbf{6} \mathrm{MI}, \mathrm{n}=7+\mathrm{X}+\mathrm{Y} \mathbf{7}$ pachytene 8 spermatids 9 mitotic metaphase $\mathbf{I} \mathbf{0}$ spermatids. Asterisks mark sex chromosomes; red signals identify the (TTAGG) ${ }_{n}$ - positive telomeres (arrowed); green signals identify rDNA clusters. Scale bar on Fig. 2 also applies to Figs 3-10.

by Kuznetsova et al. (2015). FISH with "insect" telomeric probe (TTAGG) ${ }_{n}$ produced strong hybridization signals on the chromosome ends at metaphase I (Figs 2, 3) and other stages of meiosis (not shown). Some differences in hybridization intensity could be seen among different bivalents and between homologous telomeres. The rDNA probe detected $18 \mathrm{~S} \mathrm{rDNA}$ clusters on a large pair of autosomes (Figs 2, 3).

In male $A$. occitanica, we found 8 bivalents of various sizes and the $\mathrm{X}$ and $\mathrm{Y}$ univalent chromosomes, suggesting $2 \mathrm{n}=18(16+\mathrm{XY})$. This species is cytogenetically studied for the first time. Its karyotype includes one exceptionally large pair of bi-armed autosomes, another pair of large bi-armed autosomes and the two sex chromosomes, 
with the longer metacentric chromosome presumably being the $\mathrm{X}$, while the other metacentric chromosome - the Y; the detailed morphology of other chromosomes remained unknown. The majority of bivalents and sex chromosomes displayed strong signals of the telomere probe. As for the heterogeneity for presence/absence and intensity of the (TTAGG) ${ }_{n}$ signals, it could be explained by technical artifacts. Apart from a few scattered signals, the ribosomal probe detected a considerable accumulation of the $18 \mathrm{~S}$ rDNA sequence on the second large pair of bi-armed autosomes and, additionally, on the putative $\mathrm{X}$ chromosome (Fig. 4).

In male D. tetragrammicus, we found 7 autosomal bivalents and $\mathrm{X}$ and $\mathrm{Y}$ univalent chromosomes (Figs 5, 6). An additional univalent, most likely a B-chromosome, which precociously segregates together with one of the sex chromosomes, was occasionally observed in first metaphase nuclei (not shown). The data obtained suggest a diploid karyotype of $2 \mathrm{n}=16(14+\mathrm{XY})$ in contrast to $2 \mathrm{n}=18(16+\mathrm{XY})$ reported by Kuznetsova et al. (2015). FISH with (TTAGG) ${ }_{n}$ probe has detected no hybridization signals in the first metaphase nuclei (Fig. 5). However, weak and scarce (TTAGG) hybridization signals of uncertain location could be seen in separate chromosomes of different stages as well as in the spermatids (Figs 6-8). The rDNA probe revealed $18 \mathrm{~S}$ rDNA clusters both on a large pair of autosomes (possibly the third pair), and one of the sex chromosomes (Figs 5, 6).

In male $L$. macaronius, the karyotype remained unknown. However the (TTAGG) ${ }_{n}$ -positive signals could be clearly observed in some cells including spermatids (Figs 9, 10).

\section{Discussion}

\section{Karyotypes}

As summarized recently (Kuznetsova et al. 2015), the karyotypes are currently known for 37 species of the Myrmeleontidae representing about 2.2\% of the extant antlion species. The studied species belong to 21 genera and 9 subfamilies (sensu Krivokhatsky 2011) and were shown to have an XY-sex chromosome system as well as diploid chromosome numbers ranging from 14 to 26 . The highest numbers, $2 n=22,24$ and 26 , occur only in a more basal subfamily Palparinae, whereas lower numbers, $2 \mathrm{n}=14,16$ and 18 , are encountered in other subfamilies. Since the sister group to the Myrmeleontidae, i.e. the family Ascalaphidae, is characterized by higher chromosome numbers, usually $2 \mathrm{n}=22$, a higher number was suggested to be ancestral for antlions (Kuznetsova et al. 2015). The karyotypes of $2 \mathrm{n}=16$ and $2 \mathrm{n}=18$, which we recently found in Distoleon tetragrammicus (Nemoleontinae) and Acanthaclisis occitanica (Acanthaclisinae) respectively, corroborate this assumption. These karyotypes are further discussed below.

In our previous paper (Kuznetsova et al. 2015), D. tetragrammicus was reported to have $2 \mathrm{n}=18$, i.e., having two additional pairs of autosomes. A plausible explanation for this disagreement is that a univalent displaced from the equatorial plane was erroneously identified as a bivalent at the first metaphase in the only studied male (see 
Fig. 2 in Kuznetsova et al. 2015). It is worth noting that a univalent segregating precociously with the sex chromosomes at the first metaphase was also observed in some nuclei of male $D$. tetragrammicus during the present study (see Results). We suggest that these univalent chromosomes are additional or so-called B chromosomes. One or two additional chromosomes that do not belong to the regular karyotype and are similar in their meiotic behavior to the sex chromosomes were repeatedly observed in different neuropteran species, including the antlion Myrmeleon mexicanus Banks, 1903 (Hughes-Schrader 1983). The effect of the supernumeraries varies in different species. For example, in Hemerobius marginatus Stephens, 1836 from another neuropteran family Hemerobidae, additional chromosomes influence the segregation of the sex chromosomes in meiosis (Nokkala 1986). The problem of B chromosomes in antlions needs to be further addressed in the future.

The karyotype of $A$. occitanica differs by having both very large autosomal bivalent and sex chromosome (supposedly the X). To our knowledge, this karyotype structure was never reported for the Myrmeleontidae. However, it is worth noting that antlion karyotypes were almost exclusively illustrated with drawings in the past (as opposed to photos) with no significant details of the chromosome structure and size reported.

\section{Telomeres}

The data obtained in the present study demonstrate for the first time the presence of the insect-type telomeric repeat (TTAGG) ${ }_{n}$ in antlions. We have reliably shown that this motif is characteristic of $P$. libelluloides and $A$. occitanica. The third examined antlion species, $D$. tetragrammicus, in which only rare TTAGG-positive signals of uncertain location were detected at best, most likely does not have the canonical (TTAGG) ${ }_{n}$ insect telomeric motif. However, the TTAGG sequence could actually be present in the telomeres but in very low copy numbers, making it difficult to detect this sequence by FISH. Consequently, we consider the data on $D$. tetragrammicus as preliminary and therefore deserving further clarification. We also showed that the (TTAGG) ${ }_{n}$ repeat was present in telomeres of L. macaronius (Ascalaphidae). Earlier, this telomeric motif was recorded for another owlfly species, Protidricerus japonicas, by Frydrychová et al. (2004). Together with the results on P. japonicus, our data suggest that the (TTAGG) ${ }_{n}$ telomere sequence found in species of Ascalaphidae and Myrmeleontidae was characteristic of the common ancestor of these sister families. The detection of this repeat in the most basal antlion subfamily examined so far, the Palparinae (P. libelluloides), further corroborates this suggestion.

At present, the only other neuropteran species with known telomere structure is Chrysoperla carnea s. lato belonging to the large worldwide family Chrysopidae (green lacewings). Based on the Southern hybridization results, Frydrychová et al. (2004) have shown that Ch. carnea is (TTAGG) ${ }_{n}$-negative. Despite the relatively small size of the order Neuroptera including only 5803 extant species (Oswald 2016), the data on telomere structure are still highly insufficient, and further studies are needed to fully understand the organization of telomeres in different families of this insect order. 


\section{Ribosomal clusters}

Ribosomal gene markers have provided useful information regarding chromosome evolution in different groups of insects. In some groups, the number and chromosomal localization of rDNA clusters, usually located in the nucleolus organizing regions (NORs), serve as additional markers to characterize species and higher taxa (Nguyen et al. 2010, Gokhman et al. 2014), whereas in other groups they currently are the only available cytogenetic markers to differentiate species with similar karyotypes (Golub et al. 2016). Our data represent the first mapping experiments for the major rRNA genes (i.e. genes for 18S, $5.8 \mathrm{~S}$ and 28S rRNA) not only in Myrmeleontidae but also in Neuroptera in general. The three species studied, Palpares libelulloides, Acanthaclisis occitanica and Distoleon tetragrammicus, showed the occurrence of one (in the first species) or two (in the two last species) rDNA clusters in their haploid karyotypes. In each species, these clusters are located on both autosomes of a particular large pair. In $A$. occitanica and D. tetragrammicus, another rDNA site is present on one of the sex chromosomes. Although it is at present impossible to identify homeologous chromosomes between different neuropteran species, we can suggest a single chromosome pair carrying major rDNA clusters as an ancestral state in antlions.

\section{Conclusions}

Our study contributes to the current knowledge of cytogenetics of the neuropteran family Myrmeleontidae. The principal outcomes of this study are: (1) the discovery of one or two major rDNA clusters per haploid karyotype; the clusters are located either only on a pair of autosomes in a particular species or, additionally, on one of the sex chromosomes in another two studied species and (2) the discovery of the insect-type (TTAGG) ${ }_{n}$ telomeric sequence at least in two of the three studied species. Because the (TTAGG) ${ }_{n}$ sequence is likewise found in the two studied owlfly species, we suggest that this telomere structure was inherent in the last common ancestor of the phylogenetic lineage Myrmeleontidae + Ascalaphidae.

\section{Acknowledgements}

The complete financial support for this study was provided by the grant from the Russian Science Foundation no. 14-14-00541 to the Zoological Institute of the Russian Academy of Sciences. We thank Dr. E.V. Ilyina (Dagestan Scientific Center RAS, Makhachkala) for help in collection and Dr. V.A. Krivokhatsky (Zoological Institute RAS, St. Petersburg) for help in identification of species, studied in the present paper. 


\section{References}

Badano D, Aspöck U, Aspöck H, Cerretti P (2016) Phylogeny of Myrmeleontiformia based on larval morphology (Neuropterida: Neuroptera). Systematic Entomology. doi: 10.1111/ syen. 12200

Frydrychová R, Marec F (2002) Repeated losses of TTAGG telomere repeats in evolution of beetles (Coleoptera). Genetica 115: 179-187. doi: 10.1023/A:1020175912128

Frydrychová R, Grossmann P, Trubač P, Vítková M, Marec F (2004) Phylogenetic distribution of TTAGG telomeric repeats in insects. Genome 47: 163-178. doi: 10.1139/G03-100

Gokhman VE, Anokhin BA, Kuznetsova VG (2014) Distribution of 18S rDNA sites and absence of the canonical TTAGG insect telomeric repeat in parasitoid Hymenoptera. Genetica 142: 317-322. doi: 10.1007/s10709-014-9776-3

Golub NV, Golub VB, Kuznetsova VG (2016) Further evidence for the variability of the $18 \mathrm{~S}$ rDNA loci in the family Tingidae (Hemiptera, Heteroptera). Comparative Cytogenetics 10(4): 517-527. doi: 10.3897/CompCytogen.v10i4.9631

Gomes NJW, Shay JW, Wright WE (2010) Telomere Biology in Metazoa. FEBS Letters 584(17): 3741-3751. doi: 10.1016/j.febslet.2010.07.031

Henry CS (1978) An unusual ascalaphid larva (Neuroptera:Ascalaphidae) from Southern Africa, with comments on larval evolution within the Myrmeleontoidea. Psyche 85: 265-274. doi: $10.1155 / 1978 / 19204$

Hughes-Schrader S (1983) Chromosomal segregational mechanisms in antlions (Myrmeleontidae, Neuroptera). Chromosoma 88(4): 256-264. doi: 10.1007/BF00292902

Krivokhatsky VA (2011) Antlions (Neuroptera: Myrmeleontidae) of Russia. KMK Scientific Press Ltd, St. Petersburg-Moscow, 334 pp. [In Russian]

Kuznetsova VG, Khabiev GN, Krivokhatsky VA (2015) Chromosome numbers in antlions (Myrmeleontidae) and owlflies (Ascalaphidae) (Insecta, Neuroptera). ZooKeys 538: 47-61. doi: 10.3897/zookeys.538.6655

Lukhtanov VA, Kuznetsova VG (2010) What genes and chromosomes say about the origin and evolution of insects and other arthropods. Russian Journal of Genetics 46(9): 1115-1121. doi: 10.1134/S1022795410090279

Maryańska-Nadachowska A, Anokhin BA, Gnezdilov VM, Kuznetsova VG (2016) Karyotype stability in the family Issidae (Hemiptera, Auchenorrhyncha) revealed by chromosome techniques and FISH with telomeric (TTAGG) ${ }_{n}$ and $18 \mathrm{~S}$ rDNA probes. Comparative Cytogenetics 10(3): 347-369. doi: 10.3897/CompCytogen.v10i3.9672

Nguyen P, Sahara K, Yoshido A, Marec F (2010) Evolutionary dynamics of rDNA clusters on chromosomes of moths and butterflies (Lepidoptera). Genetica 138: 343-354. doi: $10.1007 /$ s 10709-009-9424-5

Nokkala S (1986) The meiotic behaviour of B-chromosomes and their effect on the segregation of sex chromosomes in males of Hemerobius marginatus L. (Hemerobidae, Neuroptera). Hereditas 105: 221-227. doi: 10.1111/j.1601-5223.1986.tb00665.x

Okazaki S, Tsuchida K, Maekawa H, Ishikawa H, Fujiwara H (1993) Identification of a pentanucleotide telomeric sequence, (TTAGG), in the silkworm Bombyx mori and in other insects. Molecular and Cellular Biology 13: 1424-1432. doi: 10.1128/mcb.13.3.1424

Oswald JD (2016) LDL Neuropterida Species of the World (version Oct 2013). In: Roskov Y, Abucay L, Orrell T, Nicolson D, Flann C, Bailly N, Kirk P, Bourgoin T, DeWalt RE, Decock W, De Wever A (Eds) Species 2000 \& ITIS Catalogue of Life, 31 $1^{\text {st }}$ October 2016. Species 2000: Naturalis, Leiden. http://www.catalogueoflife.org/col [accessed 5 May 2016] 
Pita S, Panzera F, Mora P, Vela J, Palomeque T, Lorite P (2016) The presence of the ancestral insect telomeric motif in kissing bugs (Triatominae) rules out the hypothesis of its loss in evolutionarily advanced Heteroptera (Cimicomorpha). Comparative Cytogenetics 10(3): 427-437. doi: 10.3897/CompCytogen.v10i3.9960

Stange LA (2004) A systematic catalog, bibliography and classification of the world antlions (Insecta: Neuroptera: Myrmeleontidae). Memoirs of the American Entomological Institute 74: $1-565$.

Tjeder B (1992) The Ascalaphidae of the Afrotropical Region (Neuroptera). 1. External morphology and bionomics of the family Ascalaphidae, and taxonomy of the subfamily Haplogleniinae including the tribes Proctolyrini n. tribe, Melambrotini n. tribe, Campylophlebini n. tribe, Tmesibasini n. tribe, Allocormodini n. tribe, and Ululomyiini n. tribe of Ascalaphidae. Entomologica Scandinavica Supplement 41: 3-169.

Traut W, Szczepanowski M, Vítková M, Opitz C, Marec F, Zrzavý J (2007) The telomere repeat motif of basal Metazoa. Chromosome Research 15(3): 371-382. doi: 10.1007/ s10577-007-1132-3 